\title{
Portal vein stent placement after hepatobiliary and pancreatic surgery
}

\author{
Ammar Khan $^{1,2}$ (1) $\cdot$ Dyre Kleive $^{2,3} \cdot$ Einar Martin Aandahl ${ }^{1} \cdot$ Bjarte Fosby $^{1} \cdot$ Pål-Dag Line $^{1,2} \cdot$ Eric Dorenberg $^{4} \cdot$ \\ Steinar Guvåg ${ }^{1} \cdot$ Knut Jørgen Labori ${ }^{3}$
}

Received: 1 April 2020 / Accepted: 23 June 2020 / Published online: 3 July 2020

(C) The Author(s) 2020

\begin{abstract}
Purpose To evaluate the long-term outcomes of percutaneous transhepatic stent placement for portal vein (PV) stenosis after liver transplantation (LT) and hepato-pancreato-biliary (HPB) surgery.

Methods Retrospective study of 455 patients who underwent LT and 522 patients who underwent resection of the pancreatic head between June 2011 and February 2016. Technical success, clinical success, patency, and complications were evaluated for both groups. Results A total of 23 patients were confirmed to have postoperative PV stenosis and were treated with percutaneous transhepatic PV stent placement. The technical success rate was $100 \%$, the clinical success rate was $80 \%$, and the long-term stent patency was 91.3\% for the entire study population. Two procedure-related hemorrhages and two early stent thromboses occurred in the HPB group while no complications occurred in the LT group. A literature review of selected studies reporting PV stent placement for the treatment of PV stenosis after HPB surgery and LT showed a technical success rate of 78-100\%, a clinical success rate of 72$100 \%$, and a long-term patency of 57-100\%, whereas the procedure-related complication rate varied from 0-33.3\%.

Conclusions Percutaneous transhepatic PV stent is a safe and effective treatment for postoperative PV stenosis/occlusion in patients undergoing LT regardless of symptoms. Due to increased risk of complications, the indication for percutaneous PV stent placement after HPB surgery should be limited to patients with clinical symptoms after an individual assessment.
\end{abstract}

Keywords Portal vein $\cdot$ Interventional radiology $\cdot$ Pancreatoduodenectomy $\cdot$ Liver transplantation $\cdot$ Patency

\section{Introduction}

Portal vein (PV) stenosis is a well-known complication after liver transplantation (LT), and hepato-pancreato-biliary (HPB) surgery [1-8]. Potential symptoms related to PV stenosis are abdominal pain, liver failure, intractable ascites, and gastrointestinal bleeding [9-11] which render it as a potentially serious condition. Management of postoperative PV stenosis with percutaneous stent placement has previously been

Ammar Khan

b34651@ous-hf.no

1 Department of Transplantation Medicine, Oslo University Hospital, Sognsvannsveien 20, 0372 Oslo Norway

2 Institute of Clinical Medicine, University of Oslo, Oslo, Norway

3 Department of Hepato-Pancreato-Biliary Surgery, Oslo University Hospital, Oslo, Norway

4 Department of Radiology, Oslo University Hospital, Oslo, Norway reported to be a viable and less invasive option than laparotomy and surgical revision [12]. Even though PV stenosis is a rare complication after LT [2,3], it has recently been shown to be as high as $19.6 \%$ after pancreatoduodenectomy [13]. Regarding LT, PV stenosis is more frequent after pediatric transplantation due to size mismatch [14].

With an increasing rate of surgical resection and vascular reconstruction in HPB surgery, an increasing incidence of complications related to the PV must be anticipated [15-17]. Percutaneous transhepatic stenting of the PV has gained acceptance as a safe minimally invasive procedure with promising results [12, 18-24]. The aim of this paper is to evaluate the results of stenting of PV stenosis after LT and HPB surgery within a high-volume tertiary referral center.

\section{Materials and methods}

This was a retrospective review of all patients undergoing PV stent placement due to postoperative PV stenosis at 
Rikshospitalet, Oslo University Hospital between June 2011 and February 2016. The hospital is a tertiary referral center for all HPB surgery in the southeast health region (3 million inhabitants) and the only national center for abdominal transplantation surgery in Norway (5.3 million inhabitants). Hospital records, including radiological reports, were reviewed. Type of surgery, time from surgery to PV stent placement, and complications to the procedure were assessed. Patency was evaluated according to latest available radiological modality, as follow-up was heterogeneous. Methods for pancreatic resections and LT were performed as described elsewhere $[25,26]$. The hospital review board approved the study (2016/8365) according to the general guidelines provided by the regional ethics committee. The manuscript was completed in accordance with the STROBE statement [27].

\section{Indication for stent placement}

For patients undergoing LT, ultrasonography (US) on postoperative day (POD) 1 was performed routinely. Subsequent radiology was obtained on clinical suspicion of adverse events. Patients undergoing pancreatoduodenectomy were not subjected for routine radiology in the immediate postoperative period, but patients with concomitant PV resection had US on POD 1 and the day before discharge. The criteria for definite diagnosis of significant PV stenosis were a 3-fold increase in portal blood velocity detected by US and a minimum of 50\% PV diameter reduction on contrast-enhanced computed tomography (CT) or percutaneous transhepatic portography. PV occlusion was defined as the absence of contrast enhancement through the PV. Patients with radiological significant $\mathrm{PV}$ stenosis underwent $\mathrm{PV}$ stenting either because of clinical manifestation or as a preemptive treatment in order to avoid future complications. Hence, indication for PV stent placement was based on radiological findings, clinical manifestations, or suspicion of future adverse events related to untreated PV stenosis.

\section{Stent placement procedure}

Routinely, the procedures were performed with the patients under conscious sedation. In all patients, access to the PV was gained by percutaneous US-guided puncture of a subsegmental or segmental portal branch with introduction of a $6 \mathrm{Fr}$ introducer (Merit Medical Systems, South Jordan, UT, USA). After diagnostic angiography with confirmation of significant stenosis, stenting was performed using selfexpanding nitinol stents $40-60 \mathrm{~mm}$ in length and oversized in diameter by $1-2 \mathrm{~mm}$ as compared with the adjacent PV. For diameters of 10 and $12 \mathrm{~mm}$, we used Smart Control selfexpanding stents (Cordis, a cardinal health company, Dublin, OH, USA); in larger diameters, 14-20 mm SinusXL Flex stents (Optimed Medizinische Instrumente GmbH,
Ettingen, Germany) were placed. In cases of residual stenosis, stents were dilated with balloons at the size of the prestenotic portal segment. During removal of the introducer sheaths, gelfoam pledgets were placed in the access channel in order to prevent hemorrhage. Technical success was defined as residual stenosis $<30 \%$ or $<10 \%$ difference in pressure gradient on immediate angiography and absence of significant stenosis on early follow-up at US or CT. After the procedure, the patients received prophylactic low molecular weight heparin based on their body weight ( $150 \mathrm{IU} / \mathrm{kg} /$ day) for a minimum of 3 months. Following PV stent placement, supplementary radiology in addition to routine follow-up was obtained on clinical indication.

\section{Results}

Between June 2011 and February 2016, 455 patients underwent LT and 522 patients underwent resection of the pancreatic head (pancreatoduodenectomy $n=494$, total pancreatectomy $n=28)$. There were 14 patients $(3.1 \%)$ in the LT group and eight patients $(1.5 \%)$ in the HPB group confirmed to have postoperative PV stenosis. Six of the eight HPB patients underwent resection and reconstruction of the PV during the primary operation. In addition, one patient developed postoperative PV stenosis after a resection of the extrahepatic bile ducts. An overview of the patients is presented in Table 1. All of the 23 patients with PV stenosis/occlusion underwent a technical successful percutaneous transhepatic PV stent placement. The etiology of PV stenosis was anastomotic stenosis in 17 patients while the remaining six were caused by tumor recurrence and/or thrombosis. Only 10 of 23 patients had clinical manifestations while the remaining 13 patients had an asymptomatic PV stenosis discovered on routine radiological follow-up. Eight of 10 patients with clinical manifestations experienced disappearance of symptoms after percutaneous transhepatic PV stent placement resulting in a clinical success rate of $80 \%$. There were two procedure-related hemorrhages and two early stent thromboses in the HPB group resulting in a complication rate of $17.4 \%$ for the entire study population. Long-term stent patency for the entire study population based on the last available radiological imaging was $91.3 \%$ with a median follow-up of 6 months in the HPB group and 49 months in the LT group (Table 2).

\section{Discussion}

In this study, we investigated the outcome of PV stent placement for postoperative PV stenosis after LT and HPB surgery. PV stent placement was performed with a procedure-related complication rate of $17.4 \%$ for the entire study population, confirming the results of previous publications [11]. The 
Table 1 Overview of 23 patients receiving portal vein stent

\begin{tabular}{|c|c|c|c|c|c|c|c|}
\hline No. & Histology & Surgery & $\begin{array}{l}\text { Indication for } \\
\text { PV stent }\end{array}$ & $\begin{array}{l}\text { Resolvement of } \\
\text { symptoms }\end{array}$ & Anticoagulation & Complications & $\begin{array}{l}\text { Follow-up: stent } \\
\text { to US/CT }\end{array}$ \\
\hline 1 & $\begin{array}{l}\text { Neuroendocrine } \\
\text { tumor }\end{array}$ & Pancreatoduodenectomy & Ascites & Yes & LMWH $7500 \times 1$ & None & 926 days \\
\hline 2 & $\begin{array}{l}\text { Ampullary } \\
\text { adenocarcinoma }\end{array}$ & Pancreatoduodenectomy & Ascites & No & LMWH $7500 \times 2$ & Bleeding & 33 days \\
\hline 3 & $\begin{array}{l}\text { Distal } \\
\text { cholangiocarcino- } \\
\text { ma }\end{array}$ & Pancreatoduodenectomy & Thrombosis & No symptoms & LMWH $7500 \times 2$ & $\begin{array}{l}\text { Early stent } \\
\text { thrombosis }\end{array}$ & 282 days \\
\hline 4 & $\begin{array}{l}\text { Pancreatic ductal } \\
\text { adenocarcinoma }\end{array}$ & Pancreatoduodenectomy & $\begin{array}{l}\text { GI bleeding } \\
\text { and ascites }\end{array}$ & Yes & LMWH $5000 \times 2$ & Bleeding & 176 days \\
\hline 5 & $\begin{array}{l}\text { Pancreatic ductal } \\
\text { adenocarcinoma }\end{array}$ & Pancreatoduodenectomy & Ascites & Yes & LMWH $7500 \times 1$ & None & 1912 days \\
\hline 6 & $\begin{array}{l}\text { Pancreatic ductal } \\
\text { adenocarcinoma }\end{array}$ & Pancreatoduodenectomy & Ascites & Yes & $\begin{array}{c}\text { LMWH } 5000 \times 1+ \\
\text { lifelong aspirin }\end{array}$ & None & 152 days \\
\hline 7 & $\begin{array}{l}\text { Pancreatic ductal } \\
\text { adenocarcinoma }\end{array}$ & Pancreatoduodenectomy & Stenosis & No symptoms & LMWH $5000 \times 2$ & None & 510 days \\
\hline 8 & $\begin{array}{l}\text { Pancreatic ductal } \\
\text { adenocarcinoma }\end{array}$ & Total pancreatectomy & Stenosis & No symptoms & LMWH $5000 \times 2$ & None & 114 days \\
\hline 9 & $\begin{array}{l}\text { Distal } \\
\text { cholangiocarcino- } \\
\text { ma }\end{array}$ & Bile duct resection & Ascites & No & LMWH $5000 \times 2$ & $\begin{array}{l}\text { Early stent } \\
\text { thrombosis }\end{array}$ & 9 days \\
\hline 10 & Non-malignant & Liver transplantation & Ascites & Yes & $\begin{array}{c}\text { LMWH } 5000 \times 2+ \\
\text { lifelong aspirin }\end{array}$ & None & 1462 days \\
\hline 11 & Non-malignant & Liver transplantation & $\begin{array}{l}\text { GI bleeding } \\
\text { and ascites }\end{array}$ & Yes & $\begin{array}{c}\text { LMWH } 5000 \times 1+ \\
\text { lifelong aspirin }\end{array}$ & None & 1455 days \\
\hline 12 & Non-malignant & Liver transplantation & Thrombosis & No symptoms & LMWH $5000 \times 2$ & None & 1184 days \\
\hline 13 & Non-malignant & Liver transplantation & Stenosis & No symptoms & $\begin{array}{l}\text { LMWH } 5000 \times 1+ \\
\quad \text { lifelong aspirin }\end{array}$ & None & 2262 days \\
\hline 14 & Non-malignant & Liver transplantation & Stenosis & No symptoms & $\begin{array}{c}\text { LMWH } 5000 \times 1+ \\
\text { lifelong aspirin }\end{array}$ & None & 1813 days \\
\hline 15 & Non-malignant & Liver transplantation & Stenosis & No symptoms & LMWH $5000 \times 2$ & None & 1963 days \\
\hline 16 & Non-malignant & Liver transplantation & Stenosis & No symptoms & $\begin{array}{l}\text { LMWH } 5000 \times 1+ \\
\quad \text { lifelong aspirin }\end{array}$ & None & 731 days \\
\hline 17 & Non-malignant & Liver transplantation & Stenosis & No symptoms & $\begin{array}{c}\text { LMWH } 5000 \times 1+ \\
\text { lifelong aspirin }\end{array}$ & None & 2507 days \\
\hline 18 & Non-malignant & Liver transplantation & Stenosis & No symptoms & $\begin{array}{c}\text { LMWH } 7500 \times 1+ \\
\text { lifelong aspirin }\end{array}$ & None & 1745 days \\
\hline 19 & $\begin{array}{l}\text { Neuroendocrine } \\
\text { tumor }\end{array}$ & Liver transplantation & Stenosis & No symptoms & $\begin{array}{c}\text { LMWH } 5000 \times 2+ \\
\text { lifelong aspirin }\end{array}$ & None & 1797 days \\
\hline 20 & Cholangiocarcinoma & Liver transplantation & Stenosis & No symptoms & LMWH $5000 \times 2$ & None & 554 days \\
\hline 21 & Cholangiocarcinoma & Liver transplantation & Stenosis & No symptoms & $\begin{array}{c}\text { LMWH } 5000 \times 1+ \\
\text { lifelong aspirin }\end{array}$ & None & 25 days \\
\hline 22 & Cholangiocarcinoma & Liver transplantation & Ascites & Yes & $\begin{array}{c}\text { LMWH } 5000 \times 1+ \\
\text { lifelong aspirin }\end{array}$ & None & No US/CT \\
\hline 23 & Cholangiocarcinoma & Liver transplantation & Ascites & Yes & $\begin{array}{c}\text { LMWH } 5000 \times 1+ \\
\text { lifelong aspirin }\end{array}$ & None & 187 days \\
\hline
\end{tabular}

technical success rate was $100 \%$, the clinical success rate was $80 \%$ among patients with clinical manifestations, and the long-term stent patency was $91.3 \%$ for the entire study population. This shows that PV stenting is effective in relieving PV stenosis after LT and HPB surgery. The results of this audit are comparable with other publications; [12, 24, 28] however, comparison must be done with caution as there are obvious inter-institutional differences in the postoperative follow-up and indication of PV stent placement. In our institution, patients with clinical and/or radiological signs of significant PV stenosis were subjected to PV stenting after evaluation by a multidisciplinary team. To the best of our knowledge, there are few studies investigating which patients benefit from postoperative PV stent placement.

Among the patients with PV stent placement after LT, there were no procedure-related complications and a long-term patency of $100 \%$. This supports the decision to preemptive treat asymptomatic patients with radiological signs of significant 
Table 2 Baseline characteristics and summary of periprocedural outcomes

\begin{tabular}{|c|c|c|c|}
\hline Baseline characteristics & All & HPB surgery & Liver transplantation \\
\hline Number & 23 & 9 & 14 \\
\hline Age, median (range) & $58(33-74)$ & $62(47-74)$ & $47(33-68)$ \\
\hline Sex (male/female) & $15 / 8$ & $6 / 3$ & $9 / 5$ \\
\hline BMI, median (range) & $23(18-31)$ & $24(18-28)$ & $22(19-31)$ \\
\hline Child-Pugh classification (A/B/C) & $15 / 4 / 4$ & $9 / 0 / 0$ & $6 / 4 / 4$ \\
\hline \multicolumn{4}{|l|}{ Etiology for PV stenosis } \\
\hline Tumor recurrence & 4 & 2 & 2 \\
\hline Anastomotic stenosis & 17 & 5 & 12 \\
\hline Postoperative thrombosis & 2 & 2 & 0 \\
\hline \multicolumn{4}{|l|}{ Indication for PV stent } \\
\hline Ascites & 8 & 5 & 3 \\
\hline GI bleeding and ascites & 2 & 1 & 1 \\
\hline Asymptomatic & 13 & 3 & 10 \\
\hline \multicolumn{4}{|l|}{ Resolvement of symptoms } \\
\hline Ascites resolved & 6 & 3 & 3 \\
\hline GI bleeding and ascites resolved & 2 & 1 & 1 \\
\hline Symptoms not resolved & 2 & 2 & 0 \\
\hline Time from primary operation to stent, median (min-max), days & $177(21-1565)$ & $237(43-1565)$ & $163(21-937)$ \\
\hline Time from stent placement to last CT, median (min-max), days & $828(9-2507)$ & $176(9-1912)$ & $1462(25-2507)$ \\
\hline Complications of PV stent & $2 / 23$ & $2 / 9$ & $0 / 14$ \\
\hline Early stent occlusion $<30$ days & $2 / 23$ & $2 / 9$ & $0 / 14$ \\
\hline Patent stent on last CT & $21 / 23$ & $7 / 9$ & $14 / 14$ \\
\hline
\end{tabular}

PV stenosis after LT to reduce the risk of future complications. Importantly, PV complications after LT have been well documented because PV stenosis and thrombosis can potentially be devastating and lead to graft failure [14]. PV stenosis is more frequent after pediatric LT, and some centers have practiced an early approach to PV abnormalities during pediatric LT. A recent study showed that PV stent placement during the transplant or in the immediate postoperative setting through the inferior mesenteric vein offered both a high feasibility and satisfactory results in pediatric recipients [29].

In the HPB group, there were two procedure-related hemorrhages. One patient received PV stent 43 days after a pancreatoduodenectomy. During the PV stent placement, the patient suffered bleeding from a minor hepatic arterial branch and underwent embolization 8 days later. The patient eventually died in the intensive care unit 48 days after PV stent placement and 91 days after pancreatoduodenectomy due to pneumonia and respiratory failure due to complications after PV stent placement. The other hemorrhage was minor bleeding from the liver capsule that was successfully treated with percutaneous hemostatic applications. Another two patients experienced early stent thrombosis and permanent stent failure with a result comparable to the situation before stent placement. The possible reason for early stent occlusion in the first patient may be postoperative pancreatic fistula causing nearby inflammation and thus promoting thrombosis. The second patient had a recurrence of distal cholangiocarcinoma around the PV with resulting subtotal PV occlusion eight months after bile duct resection. Two days after PV stent placement, early stent thrombosis was confirmed with possible cause being thrombophilia in a palliative patient with advanced metastatic cancer surrounding the PV.

A summary of selected studies reporting PV stent placement for the treatment of PV stenosis after HPB surgery and LT are presented in Table 3. The studies show a technical success rate of $78-100 \%$, a clinical success rate of 72 $100 \%$, and a long-term patency of $57-100 \%$. The procedurerelated complication rate varied from $0-33.3 \%$. In the current study, PV stent placement was performed on three HPB patients with asymptomatic PV stenosis. Of note, in other published studies, PV stent placement after HPB surgery was only performed in patients with symptoms of PV stenosis such as ascites, gastrointestinal bleeding, or liver dysfunction (Table 3). Thus, it may be questioned if patients with asymptomatic stenosis should undergo PV stenting after HPB surgery. Kang et al. showed that about 20\% (162 of 826) of patients undergoing pancreatoduodenectomy developed PV stenosis/occlusion, with a significantly higher rate in patients who underwent PV resection [13]. Moreover, 13\% (21 of 162) of the patients with PV stenosis/occlusion developed gastric or 


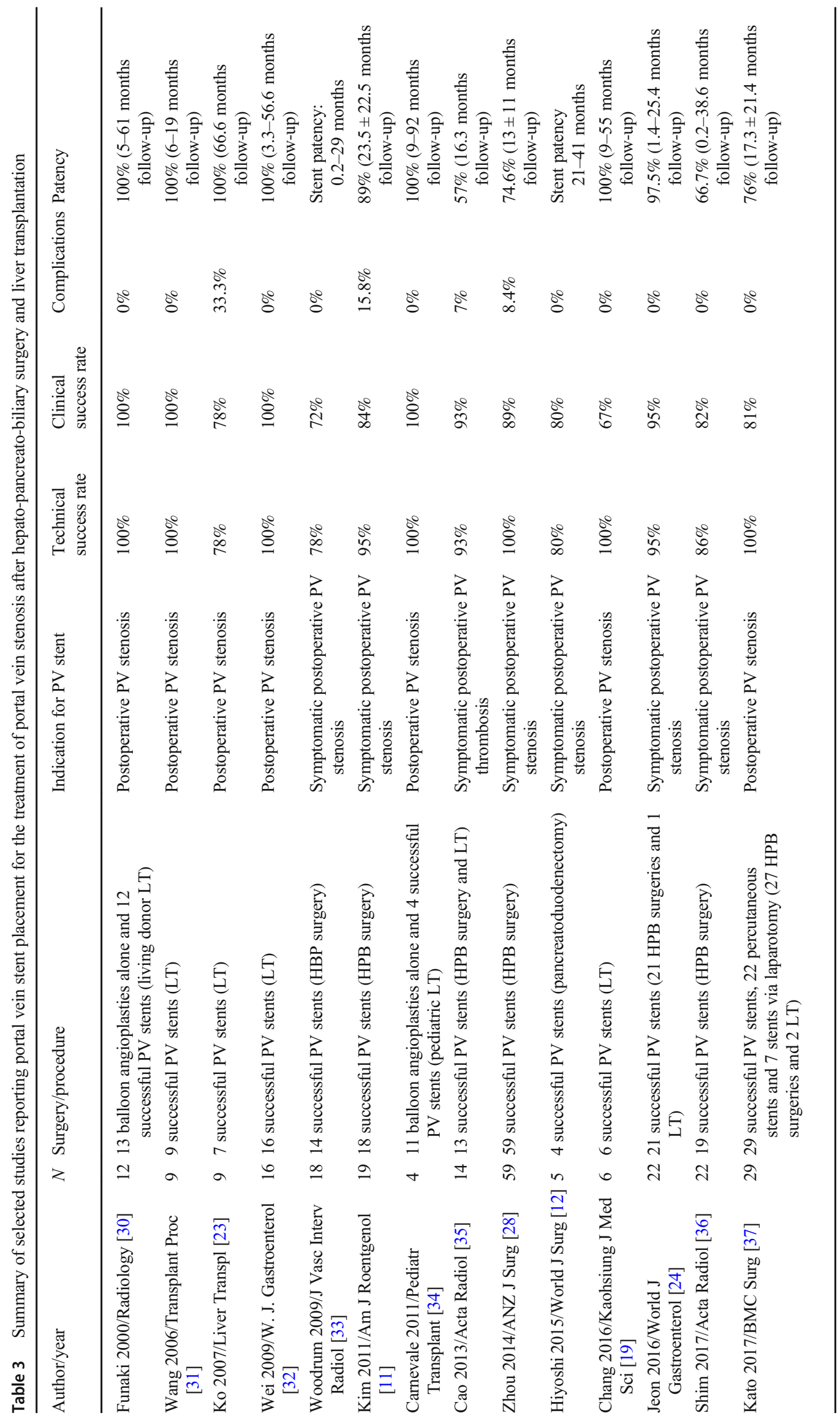


hepaticojejunostomy varices. Accordingly, the authors recommended careful postoperative surveillance for PV stenosis/ occlusion after pancreatoduodenectomy. However, although $21 \%$ (5 of 21) of the patients with gastrointestinal bleeding experienced fatal recurrent bleedings, routine PV stenting is not generally recommended in patients with asymptomatic PV occlusion because the incidence of complications related to PV stenting is seemingly higher than the rate of gastrointestinal bleeding caused by portal hypertension. However, an aggressive approach including PV stenting or selective surgical therapy to lower PV hypertension is recommended in patients who develop recurrent gastrointestinal bleeding. For patients with symptomatic PV stenosis/occlusion caused by unresectable malignant tumors, attempts have been made to identify groups that benefit from PV stenting, but results remain inconclusive mainly due to small study samples [38]. Most of these patients have advanced disease and it is difficult to predict whether PV stent placement can provide a survival benefit in this subgroup of patients.

Vascular interventional procedures may be contraindicated in the very early postoperative period $(<3$ weeks) due to the risk of suture dehiscence and anastomotic bleeding. This did, however, not pose a problem in our study and the shortest time from primary operation to PV stent placement was 21 days. Concerns about the long-term stent patency have been reported $[28,39,40]$. The role of anticoagulation regarding PV stent placement is not well established. Our strategy was prophylactic low molecular weight heparin based on their body weight $(150 \mathrm{IU} / \mathrm{kg} / \mathrm{day})$ for a minimum of three months. Aspirin was not routinely used; however, patients using aspirin before surgery continued their lifelong regimen throughout the hospital stay. In several studies $[8,9,22,40-43]$, no routine administration of anticoagulation was given as the risk of gastrointestinal bleeding was weighed against portal stent thrombosis. In our experience, the indication for anticoagulation after PV stent placement is very strong in patients with an intravascular thrombogenic foreign body in the PV sometimes combined with a malignant disease. The risk of gastrointestinal bleeding is also significantly reduced after a normal portal flow is reestablished. Our routine administration of anticoagulation may be a possible cause of acceptable long-term stent patency.

The limitations of this study lay in the retrospective design. The study sample was small and the study population was highly heterogeneous with respect to procedures being performed and causes of PV stenosis/occlusion. Nevertheless, we experienced an acceptable short- and long-term outcome. However, it is difficult to draw manifest conclusions and the findings of the study must be interpreted with caution. The literature review revealed that only two of 14 published papers have included more patients ( 29 and 59, respectively) than the 23 patients in the current study. Thus, it will be difficult to gather a larger collective of patients with this condition within a reasonable time span, even for high-volume referral centers. Management of anticoagulation after stenting and differences between collectives after liver transplant or HPB surgery are topics that should be further investigated. Moreover, a future meta-analysis of published studies on this topic could be useful. In conclusion, our results support the use of percutaneous transhepatic PV stent as a safe and effective treatment for postoperative PV stenosis or occlusion in patients undergoing LT regardless of symptoms. Due to increased risk of complications, the indication for percutaneous PV stent placement after HPB surgery should be limited to patients with clinical symptoms after an individual assessment.

Authors' contributions Study conception and design: KJL and DK; acquisition of data: all authors; analysis and interpretation of data: all authors; drafting the manuscript: $\mathrm{AK}, \mathrm{DK}$, and KJL; critical revision of the manuscript: all authors.

Funding Information Open Access funding provided by University of Oslo (incl Oslo University Hospital).

\section{Compliance with ethical standards}

Conflict of interest The authors declare that they have no conflict of interest.

Ethical approval All procedures performed in studies involving human participants were in accordance with the ethical standards of the institutional and/or national research committee and with the 1964 Helsinki declaration and its later amendments or comparable ethical standards.

Informed consent Informed consent was not obtained by all participants. The study was permitted by the hospital review board in accordance with the regional ethical committee.

Open Access This article is licensed under a Creative Commons Attribution 4.0 International License, which permits use, sharing, adaptation, distribution and reproduction in any medium or format, as long as you give appropriate credit to the original author(s) and the source, provide a link to the Creative Commons licence, and indicate if changes were made. The images or other third party material in this article are included in the article's Creative Commons licence, unless indicated otherwise in a credit line to the material. If material is not included in the article's Creative Commons licence and your intended use is not permitted by statutory regulation or exceeds the permitted use, you will need to obtain permission directly from the copyright holder. To view a copy of this licence, visit http://creativecommons.org/licenses/by/4.0/.

\section{References}

1. Yamakado K, Nakatsuka A, Tanaka N, Fujii A, Isaji S, Kawarada Y, Takeda K (2001) Portal venous stent placement in patients with pancreatic and biliary neoplasms invading portal veins and causing portal hypertension: initial experience. Radiology. 220(1):150-156

2. Olcott EW, Ring EJ, Roberts JP, Ascher NL, Lake JR, Gordon RL (1990) Percutaneous transhepatic portal vein angioplasty and stent placement after liver transplantation: early experience. J Vasc Interv Radiol 1(1):17-22 
3. Haskal ZJ, Naji A (1993) Treatment of portal vein thrombosis after liver transplantation with percutaneous thrombolysis and stent placement. J Vasc Interv Radiol 4(6):789-792

4. Yamakado K, Tanaka N, Nakatsuka A, Matsumura K, Takase K, Takeda K (1999) Clinical efficacy of portal vein stent placement in patients with hepatocellular carcinoma invading the main portal vein. J Hepatol 30(4):660-668

5. Funaki B, Rosenblum JD, Leef JA, Hackworth CA, Szymski GX, Alonso EM, Piper JB, Whitington PF (1995) Portal vein stenosis in children with segmental liver transplants: treatment with percutaneous transhepatic venoplasty. AJR Am J Roentgenol 165(1):161165

6. Funaki B, Rosenblum JD, Leef JA, Hackworth CA, Szymski GX, Alonso EM (1997) Angioplasty treatment of portal vein stenosis in children with segmental liver transplants: mid-term results. AJR Am J Roentgenol 169(2):551-554

7. Raby N, Karani J, Thomas S, O’Grady J, Williams R (1991) Stenoses of vascular anastomoses after hepatic transplantation: treatment with balloon angioplasty. AJR Am J Roentgenol 157(1):167-171

8. Vogelzang RL, Reddy SG, Braun MA, Nemcek AA Jr (1996) Extrahepatic portal venous stenosis: treatment with percutaneous transhepatic stent placement. J Vasc Interv Radiol 7(2):269-271

9. Harville LE, Rivera FJ, Palmaz JC, Levine BA (1992) Variceal hemorrhage associated with portal vein thrombosis: treatment with a unique portal venous stent. Surgery. 111(5):585-590

10. Teisseire R, Clanet J, Broussy P, Cassigneul J, Fourtanier G, Pascal JP (1979) Transjugular approach to the portal venous system. Applications to the diagnosis, prognosis and treatment of gastrointestinal bleeding in cirrhosis (author's transl). Gastroenterol Clin Biol 3(5):425-432

11. Kim KR, Ko GY, Sung KB, Yoon HK (2011) Percutaneous transhepatic stent placement in the management of portal venous stenosis after curative surgery for pancreatic and biliary neoplasms. AJR Am J Roentgenol 196(4):W446-W450

12. Hiyoshi M, Fujii Y, Kondo K, Imamura N, Nagano M, Ohuchida J (2015) Stent placement for portal vein stenosis after pancreaticoduodenectomy. World J Surg 39(9):2315-2322

13. Kang MJ, Jang JY, Chang YR, Jung W, Kim SW (2015) Portal vein patency after pancreatoduodenectomy for periampullary cancer. $\mathrm{Br}$ J Surg 102(1):77-84

14. Woo DH, Laberge JM, Gordon RL, Wilson MW, Kerlan RK Jr (2007) Management of portal venous complications after liver transplantation. Tech Vasc Interv Radiol 10(3):233-239

15. Dokmak S, Aussilhou B, Calmels M, Maghrebi H, Ftériche FS, Soubrane O, Sauvanet A (2018) Laparoscopic pancreaticoduodenectomy with reconstruction of the mesentericoportal vein with the parietal peritoneum and the falciform ligament. Surg Endosc 32(7):3256-3261

16. Dokmak S, Aussilhou B, Sauvanet A, Nagarajan G, Farges O, Belghiti J (2015) Parietal peritoneum as an autologous substitute for venous reconstruction in hepatopancreatobiliary surgery. Ann Surg 262(2):366-371

17. Line PD, Hagness M, Berstad AE, Foss A, Dueland S (2015) A novel concept for partial liver transplantation in nonresectable colorectal liver metastases: the RAPID concept. Ann Surg 262(1):e5e9

18. Patel R, Mahaveer J, Tahir N, Rajwal S, McClean P, Patel JV (2018) Outcomes of percutaneous portal vein intervention in a single UK paediatric liver transplantation programme. Cardiovasc Intervent Radiol 41(1):96-103
19. Chang WT, Kuo YT, Lee KT, Shih MC, Huang JW, Su WL, Chen CY, Huang YL, Wang SN, Chuang SC, Kuo KK, Chen JS (2016) The value of primary vascular stents in management of early portal vein stenosis after liver transplantation. Kaohsiung J Med Sci 32(3): $128-134$

20. Kamel R, Hatata Y, Taha M, Hosny K, Amin A (2015) Major vascular complications in living-donor liver transplant recipients: single center team experience. Exp Clin Transplant 13(Suppl 1): 64-70

21. Vignali C, Cioni R, Petruzzi P, Cicorelli A, Bargellini I, Perri M, Urbani L, Filipponi F, Bartolozzi C (2004) Role of interventional radiology in the management of vascular complications after liver transplantation. Transplant Proc 36(3):552-554

22. Tsukamoto T, Hirohashi K, Kubo S, Tanaka H, Hamba H, Shuto T, Higaki I, Takemura S, Kinoshita H (2003) Percutaneous transhepatic metallic stent placement for malignant portal vein stenosis. Hepatogastroenterology. 50(50):453-455

23. Ko GY, Sung KB, Yoon HK, Lee S (2007) Early posttransplantation portal vein stenosis following living donor liver transplantation: percutaneous transhepatic primary stent placement. Liver Transpl 13(4):530-536

24. Jeon UB, Kim CW, Kim TU, Choo KS, Jang JY, Nam KJ, Chu CW, Ryu JH (2016) Therapeutic efficacy and stent patency of transhepatic portal vein stenting after surgery. World J Gastroenterol 22(44):9822-9828

25. Kleive D, Sahakyan MA, Berstad AE, Verbeke CS, Gladhaug IP, Edwin B, Fosby B, Line PD, Labori KJ (2017) Trends in indications, complications and outcomes for venous resection during pancreatoduodenectomy. Br J Surg 104(11):1558-1567

26. Belghiti J, Noun R, Sauvanet A (1995) Temporary portocaval anastomosis with preservation of caval flow during orthotopic liver transplantation. Am J Surg 169(2):277-279

27. von Elm E, Altman DG, Egger M, Pocock SJ, Gøtzsche PC, Vandenbroucke JP, STROBE Initiative (2007) The Strengthening the Reporting of Observational Studies in Epidemiology (STROBE) statement: guidelines for reporting observational studies. Lancet. 370(9596):1453-1457

28. Zhou ZQ, Lee JH, Song KB, Hwang JW, Kim SC, Lee YJ, Park KM (2014) Clinical usefulness of portal venous stent in hepatobiliary pancreatic cancers. ANZ J Surg 84(5):346-352

29. Czerwonko ME, Pekolj J, Mattera J, Peralta OA, García-Mónaco RD, de Santibañes E, de Santibañes M (2019) Intraoperative stent placement for the treatment of acute portal vein complications in pediatric living donor liver transplantation. Langenbeck's Arch Surg 404(1):123-128

30. Funaki B, Rosenblum JD, Leef JA, Zaleski GX, Farrell T, Lorenz J, Brady L (2000) Percutaneous treatment of portal venous stenosis in children and adolescents with segmental hepatic transplants: longterm results. Radiology. 215(1):147-151

31. Wang JF, Zhai RY, Wei BJ, Li JJ, Jin WH, Dai DK, Yu P (2006) Percutaneous intravascular stents for treatment of portal venous stenosis after liver transplantation: midterm results. Transplant Proc 38(5):1461-1462

32. Wei BJ, Zhai RY, Wang JF, Dai DK, Yu P (2009) Percutaneous portal venoplasty and stenting for anastomotic stenosis after liver transplantation. World J Gastroenterol 15(15):1880-1885

33. Woodrum DA, Bjarnason H, Andrews JC (2009) Portal vein venoplasty and stent placement in the nontransplant population. J Vasc Interv Radiol 20(5):593-599

34. Carnevale FC, de Tarso MA, Moreira AM, Dos Santos AC, da Motta-Leal-Filho JM, Suzuki L, Cerri GG, Tannuri U (2011) Long-term results of the percutaneous transhepatic venoplasty of 
portal vein stenoses after pediatric liver transplantation. Pediatr Transplant 15(5):476-481

35. Cao G, Ko GY, Sung KB, Yoon HK, Gwon DI, Kim JH (2013) Treatment of postoperative main portal vein and superior mesenteric vein thrombosis with balloon angioplasty and/or stent placement. Acta Radiol 54(5):526-532

36. Shim DJ, Shin JH, Ko GY, Kim Y, Han K, Gwon DI, Ko HK (2017) Portal vein stent placement with or without varix embolization of jejunal variceal bleeding after hepatopancreatobiliary surgery. Acta Radiol 58(4):423-429

37. Kato A, Shimizu H, Ohtsuka M, Yoshitomi H, Furukawa K, Miyazaki M (2017) Portal vein stent placement for the treatment of postoperative portal vein stenosis: long-term success and factor associated with stent failure. BMC Surg 17(1):11

38. Hasegawa T, Yamakado K, Takaki H, Nakatsuka A, Uraki J, Yamanaka T, Fujimori M, Mizuno S, Isaji S, Sakuma H (2015) Portal venous stent placement for malignant portal venous stenosis or occlusion: who benefits? Cardiovasc Intervent Radiol 38(6): $1515-1522$

39. Yamakado K, Nakatsuka A, Tanaka N, Fujii A, Terada N, Takeda K (2001) Malignant portal venous obstructions treated by stent placement: significant factors affecting patency. J Vasc Interv Radiol 12(12):1407-1415

40. Novellas S, Denys A, Bize P, Brunner P, Motamedi JP, Gugenheim J, Caroli FX, Chevallier P (2009) Palliative portal vein stent placement in malignant and symptomatic extrinsic portal vein stenosis or occlusion. Cardiovasc Intervent Radiol 32(3):462-470

41. Dagenais M, Pomier-Layrargues G, Dufresne MP, Lapointe R, Roy A, Fenyves D (1994) Transhepatic portal vein stenting for treatment of ruptured duodenopancreatic varices in a patient with chronic pancreatitis. Surgery. 115(6):669-673

42. Hiraoka K, Kondo S, Ambo Y, Hirano S, Omi M, Okushiba S, Katoh H (2001) Portal venous dilatation and stenting for bleeding jejunal varices: report of two cases. Surg Today 31(11):1008-1011

43. Burger JA, Ochs A, Wirth K, Berger DP, Mertelsmann R, Engelhardt R, Roessle M, Haag K (1997) The transjugular stent implantation for the treatment of malignant portal and hepatic vein obstruction in cancer patients. Ann Oncol 8(2):200-202

Publisher's note Springer Nature remains neutral with regard to jurisdictional claims in published maps and institutional affiliations. 